\title{
Meeting highlights from the Committee for Medicinal Products for Human Use, 18-21 February 2008
}

\section{First pre-pandemic influenza vaccine receives positive opinion}

The European Medicines Agency's (EMEA) Committee for Medicinal Products for Human Use (CHMP) has adopted a positive opinion recommending the granting of a marketing authorisation for the first pre-pandemic influenza vaccine, Prepandrix (split inactivated, adjuvanted, H5N1 influenza vaccine containing antigens from A/VietNam/1194/2004 NIBRG-14), from GlaxoSmithKline Biologicals S.A.

Pre-pandemic vaccines are vaccines prepared from influenza viruses with a pandemic potential that are intended for use before a pandemic is declared or during an officially declared influenza pandemic. EMEA review began on 24 January 2007 with an active review time of 189 days. A separate press release is available here: http://www.emea.europa.eu/pdfs/human/press/pr/PR_H5N1_9069408en.pdf.

In addition, the CHMP has adopted a positive opinion recommending the granting of a marketing authorisation for Pandemrix (split inactivated, adjuvanted, H5N1 influenza vaccine containing antigens from A/VietNam/1194/2004 NIBRG-14), from GlaxoSmithKline Biologicals S.A. Pandemrix is a mockup pandemic influenza vaccine, intended for the prevention of influenza during an officially declared pandemic influenza situation, once the pandemic viral strain has been included. It is the third mock-up pandemic influenza vaccine to receive a positive opinion from the Committee. EMEA review began on 21 February 2007 with an active review time of 161 days.

A question-and-answer document on mock-up pandemic influenza vaccines is available here: http://www.emea.europa.eu/pdfs/general/direct/pr/50155706en.pdf.

Media enquiries only to: Martin Harvey Allchurch or Monika Benstetter

Tel.: +44207418 8427 E-mail: press@emea.europa.eu 